\title{
A ressignificação do fenômeno da loucura e da assistência à saúde mental a partir do paradigma da Reforma Psiquiátrica
}

Giselli Avíncula

Mestre em Ciências Sociais pela Universidade Federal Rural do Rio de Janeiro Professora de Sociologia da Secretaria de Estado de Educação do Rio de Janeiro. E-mail: g_avincula@hotmail.com 


\section{Resumo}

O presente artigo, por meio de um estudo teórico, apresenta a concepção e transformação do conceito de "loucura" e como histórica e culturalmente o surgimento da Psiquiatria, como especialidade da medicina dedicada ao fenômeno da "loucura", deteve o exclusivo conjunto de saberes, poderes e práticas médicas legítimas sobre a concepção, tratamento e cura da "loucura", tornando-a "doença mental". Para tal, foram tomados autores e teorias que permitiram levantar e discutir articulações sociohistóricas do campo da Reforma Psiquiátrica sobre o rompimento do paradigma psiquiátrico tradicional e do modelo hospitalocêntrico em prol da reorientação dos serviços de assistência. Finalizamos ressaltando que a Reforma Psiquiátrica é compreendida por um múltiplo movimento de desconstrução do modelo hospitalar de assistência e de construção de uma rede substitutiva para a reabilitação clínica e psicossocial, promovendo a saúde mental dos sujeitos em sofrimento psíquicos em bases comunitárias e territoriais.

Palavras-chave: Psiquiatria. Reforma Psiquiátrica. Saúde Mental.

\section{Abstract}

The present article, through a theoretical study, presents the conception and transformation of the concept of "madness" and how, historically and culturally, the emergence of Psychiatry, as a specialty of medicine dedicated to the phenomenon of "madness", stopped the exclusive set of knowledge, powers and legitimate medical practices on the design, treatment and cure of "madness", making it "mental illness." For that, authors and theories were taken that allowed to raise and discuss sociohistorical articulations of the Psychiatric Reform field on the rupture of the traditional psychiatric paradigm and the hospital-centered model in favor of the reorientation of the assistance services. We conclude by stressing that the Psychiatric Reform is understood by a multiple deconstruction movement of the hospital model of care and construction of a substitutive network for clinical and psychosocial rehabilitation, promoting the mental health of mentally ill individuals on a community and territorial basis.

Keywords: Psychiatry. Psychiatric Reform. Mental Health. 


\section{Introdução}

O objetivo deste artigo é apresentar o histórico dos aspectos sobre a "loucura" construído por saberes, práticas e instituições que transformaram a "loucura" num campo do conhecimento científico e de intervenção social. Para tal, foram tomadas a pesquisa bibliográfica e a consulta documental como método de forma a elencar autores e teorias sobre a transmutação da concepção de doença mental para perspectiva da promoção da saúde mental.

Inicialmente discutimos breves articulações históricas das apropriações de como os discursos da ciência e do poder direcionaram as relações com a "loucura", estabelecendo relações de controle no qual a Psiquiatria se torna responsável pela "loucura" na figura do médico psiquiatra, detentor do saber médico-científico, e do manicômio como local exclusivo de tratamento e cura.

Expusemos como a "loucura" tornou-se um dispositivo, nos termos de Foucault (1977, 2010), demonstrando que as metamorfoses do conceito de loucura, explicitado pelo autor, reduziu-se à noção de "desatino" e "adoecimento" como justificativa para a segregação e coerção da população considerada "desviante" (VELHO, 1974; GOFFMAN, 1988, 2010). Na sequência situamos o nascimento da Psiquiatria que se constituiu como ciência médica especializada nos saberes e procedimentos terapêuticos dirigidos ao "doente mental", além de indicar o nascimento do manicômio como lugar físico e simbólico de degredo e tratamento da população "alienada" e "desviante".

No entanto, paralelamente, focalizamos o movimento da Reforma Psiquiátrica (RP) no Brasil e no mundo pela crítica e o questionamento a este modelo psiquiátrico instituído, objetivando a transformação ou até mesmo extinção dos hospitais psiquiátricos existentes. Caracterizamos o movimento da Reforma Psiquiátrica como um processo político e social complexo em torno do paradigma da "desinstitucionalização" (ROTELLI, 1990, 1992), que compreende esforços de vários agentes em prol das transformações epistemológicas, das tecnologias do cuidado e no modelo de assistência à saúde mental, segundo as diretrizes da Lei 10.216/2001 e diversas Portarias Ministeriais, que estabelecem a reabilitação clínica e psicossocial, em bases comunitárias e territoriais, e a autonomia e reinserção social dos sujeitos que vivenciam o "sofrimento psíquico". 
Por fim, relatamos como a atuação dos movimentos da Reforma Psiquiátrica pela produção de novos conceitos, novas funções e novas percepções sobre a "loucura", enalteceu a concepção de "saúde mental" em detrimento da noção de "doença mental".

\title{
A psiquiatria tradicional e a psiquiatrização da loucura: manicômios e o modelo hospitalocêntrico
}

\begin{abstract}
Manicômio é sinônimo de um certo olhar, de um certo conceito, de um certo gesto que classifica desclassificando, que inclui excluindo, que nomeia desmerecendo, que vê sem olhar (AMARANTE, 1999, p.49).
\end{abstract}

Os saberes, discursos e práticas médicas que inauguraram a Psiquiatra são analisados por Michel Foucault (2010) em sua obra História da Loucura na Idade Clássica. O livro apresenta a metamorfose do conceito de "loucura" desde a era renascentista à moderna, reconstruindo a significação, em diferentes períodos da humanidade, que cada sistema cultural atribuiu ao fenômeno da "loucura".

A transformação social do conceito de "loucura", com advento do Racionalismo, desvencilhou-se da perspectiva da alteridade, das forças da natureza ou da divindade, e impregnou-se da dialética razão-desrazão evidenciada por uma alteração na relação do sujeito com a realidade (FOUCAULT, 2010). Dessa forma, o "louco" passava a ser aquele que transgride ou ignora as normatividades estabelecidas pelas instituições sociais (Família, Igreja, Direito, Estado, Trabalho). Por conseguinte, é estigmatizado através do que Goffman (2010, 1988) denominou "identidade deteriorada". Essa identidade está associada, entre outras coisas, à periculosidade e insensatez necessitando de um controle social investido de um poder disciplinador que somente o asilo, enquanto "instituição total" pode proporcionar. Erving Goffman (2010) define a noção de "instituição total" como:

(...) um local de residência e trabalho onde um grande número de indivíduos com situação semelhante, separados da sociedade mais ampla por considerável período de tempo, levam uma vida fechada e formalmente administrada (GOFFMAN, 2010, p.11). 
Esse fechamento e isolamento do mundo externo, proporcionado pelos asilos, são materializados na sua estrutura física com altos muros, trancas, cadeados, grades, vigilância ostensiva e forte coerção social sobre os internos.

A organização de um lugar de cárcere para o "louco" instaurou o nascimento da Psiquiatria como uma área da medicina voltada ao estudo do fenômeno da "loucura", passando a formular dispositivos teóricos e práticos sobre a "doença mental". A "desrazão" passou a ser o objeto de conhecimento da psiquiatria. Esse paradigma se legitimou no ocidente, sobretudo nos séculos XVIII, XIX e metade do XX. Amarante (1995a) aponta o deslocamento da concepção de loucura do universo simbólico para o patológico, instaurando, portanto, o nascimento da psiquiatria e a psiquiatrização da loucura:

\begin{abstract}
Acompanhamos, assim, a passagem de uma visão trágica da loucura para uma visão crítica. A primeira permite que a loucura, inscrita no universo da diferença simbólica, se permita um lugar social reconhecido no universo da verdade; ao passo que a visão crítica organiza um lugar de encarceramento, morte e exclusão para o louco. Tal movimento é marcado pela constituição da medicina mental como campo do saber teórico/prático. A partir do século XIX, há a produção de uma percepção dirigida pelo olhar científico sobre o fenômeno da loucura e sua transformação em objeto de conhecimento: a doença mental. Tal passagem tem no dispositivo de medicalização e terapeutização a marca histórica de constituição da prática médica psiquiátrica. (AMARANTE, 1995a, p.23).
\end{abstract}

Dessa forma o "louco" caracterizado como figura de risco e periculosidade institucionalizou o poder da psiquiatria tanto como o campo médico destinado à investigação científica da "doença mental" e ao seu cuidado; quanto os profissionais que são dotados do controle, organização e gestão do espaço hospitalar que segrega o indivíduo que se desvia do padrão de razão ocidental.

$\mathrm{Na}$ década de 1940, Canguilhem (2006) problematizou os conceitos de "normalidade" e "anormalidade" que ancoravam os diagnósticos biomédicos sobre a detecção da "loucura". O autor argumentou que as classificações sobre patologia estão sempre relacionadas às concepções sobre "normalidade". Portanto os parâmetros sobre o "normal" e o "patológico" são construídos a partir do referencial sociocultural, em um dado período histórico, vinculado aos padrões comportamentais estabelecidos pelas instituições sociais. 
Nessa perspectiva, os comportamentos que expressassem desarmonia com as normalidades vigentes do sistema social, segundo as instituições sociais como a Ciência, em particular a Medicina Psiquiátrica, foram classificados como expressões de "loucura", ficando estabelecida a prática social do asilo como procedimento terapêutico para o indivíduo considerado inapto ao convívio social. Tal apropriação da noção de "louco" pelo saber médico moderno, conforme estudos de Foucault (2010), consistia em tratá-lo como "doente mental", definindo um status social patológico sendo a reclusão e a disciplina sinônimos de assistência médica e cuidados terapêuticos.

Nesse paradigma psiquiátrico, os médicos Phillipe Pinel e Eugene Morel (AMARANTE e COSTA, 2012) tiveram a primazia de cunhar termos, à época, considerados objetivos, ou seja, científicos, para abordar o tema da "loucura": o primeiro definiu o conceito de "alienação" associado efetivamente à destituição da razão. Através dessa noção, contribuiu-se para a instituição da noção de periculosidade ao associar a "loucura" à incapacidade de discernimento da realidade, restando-lhe apenas o isolamento e o controle social. Para complementação da nosografia da "doença mental" os conceitos de "degeneração" e "demência", nomeados por Morel, estipulavam o caráter irreversível da "doença mental", a qual acometeria o indivíduo ao progressivo dano da cognição.

Robert Castel (1978) definiu bem os princípios da tecnologia alienista alardeada por Pinel que promoveu a institucionalização da psiquiatria e dos primeiros conceitos associados à "doença mental". Philiphe Pinel ao distinguir o "louco" do criminoso, ao libertar os pacientes dos manicômios das correntes, engendrou ações que "abriram o asilo ao conhecimento médico" (FOUCAULT, 2010, p.498) ao designar então a "loucura" como "desrazão", como "doença mental". Segundo Castel:

Pinel reuniu essas três dimensões, heterogêneas em aparência cuja articulação vai constituir a síntese alienista: classificação do arranjo institucional, arranjo nosográfico das doenças mentais, imposição de uma relação específica de poder entre o médico e doente, 'o tratamento moral' . (CASTEL, 1978, p.81).

Nesse sentido, o manicômio, e toda tradição asilar estabeleceu-se como um dispositivo de reclusão, coerção, violência, vigilância ostensiva e poder disciplinar (FOUCAULT, 2010), onde "inadaptados" eram segregados do convívio social e distribuídos nos espaços asilares de forma a facilitar o sistema de vigilância por meio de técnicas, como, por exemplo, a clausura. Os indivíduos conflitantes com o código moral 
e as normatividades sociais representavam uma ameaça ao sistema social, pois "poluíam" a ordem social, por sua condição "impura" (DOUGLAS, 1971).

Segundo Mary Douglas (1971) "impureza" significa ofensa contra a ordem classificatória, a contaminação possui alto grau simbólico, razão pela qual os esforços visando extirpar a "impureza" ameaçadora das normatividades são representados pelas mobilizações de instituições e grupos sociais em prol da organização social. A ameaça às normas sociais "contamina" as relações sociais, estendendo os conceitos de "puro/impuro" a pessoas e grupos sociais. Cada organização sociocultural impõe sua própria noção de "sujeira" e de "contaminação", e assim estabelece sua noção de ordem. A partir de então, a "sujeira" deve ser eliminada. Dessa forma, as noções de "pureza" e "impureza" fundam pilares constitutivos para normatizações que classificam a experiência humana e regulamentam a rede de relações sociais, definindo os padrões de comportamento social, moral e ético.

Deste modo, pares dicotômicos como "saúde/doença", "normal/patológico", "razão/desrazão" seguem a lógica dialética do "puro/impuro", em que polaridades são necessárias para que a ordem se crie. Isto implica dizer que o encarceramento de idosos, crianças abandonadas, pessoas com necessidades especiais, população em situação de rua, prostitutas, pessoas com doenças venéreas e sistematicamente, os "loucos", na lógica manicomial, atende à prerrogativa do controle social de tudo que fosse desviante e comprometesse a continuidade da estrutura de um sistema social (FOUCAULT, 2010).

Foucault (1977) caracterizou o poder disciplinar como expressão das relações sociais instituindo um controle social que dociliza, adestra e classifica as pessoas por meio das normas socialmente estabelecidas pelas instituições:

O poder disciplinar é, com efeito, um poder que em vez de se apropriar e de retirar, tem como função maior "adestrar"; ou sem dúvida adestrar para retirar e se apropriar ainda mais e melhor. Ele não amarra as forças para reduzi-las; procura ligá-las para multiplicá-las e utilizá-las num todo. Em vez de dobrar uniformemente e por massa tudo o que lhe está submetido, separa, analisa, diferencia, leva seus processos de decomposição até às singularidades necessárias e suficientes. "Adestra" as multidões confusas, móveis, inúteis de corpos e forças para uma multiplicidade de elementos individuais - pequenas células separadas, autonomias orgânicas, identidades e continuidades genéticas, segmentos combinatórios. A disciplina "fabrica" indivíduos; ela 
é a técnica específica de um poder que toma os indivíduos ao mesmo tempo como objetos e como instrumentos de seu exercício. (FOUCAULT, 1977, p.143)

Portanto, a fundação da psiquiatria se deu com a institucionalização da "loucura", através da reforma da instituição hospitalar, inaugurando a figura dos hospitais psiquiátricos que encarceraram "desviantes" que atendessem à classificação nosográfica das doenças mentais até então catalogadas pela psiquiatria tradicional "alienados", "dementes", "degenerados".

Howard Becker (1971 apud VELHO, 1974) problematizou o termo "desviantes" considerando que grupos dominantes, ao criarem as normas vigentes, são também os criadores do "desvio", conquanto a não observância das regras traduz "desvio", uma vez identificado em certos indivíduos, estes recebem a marca de "outsiders" (de fora, estrangeiros, estranhos).

Sobre a estigmatização do "desvio", Becker nos diz que:

(...) sob tal ponto de vista, o desvio não é uma qualidade do ato que a pessoa faz, mas sim a consequência da aplicação por outrem de regras e sanções ao 'transgressor'. O desviante é aquele a quem tal marca foi aplicada com sucesso, o comportamento desviante é o comportamento assim definido por pessoas concretas (1971 apud VELHO, 1974, p.24).

Gilberto Velho destaca a perspectiva do "desvio" através do viés médico e do cuidado terapêutico:

\footnotetext{
Tradicionalmente, o indivíduo desviante tem sido encarado a partir de uma perspectiva médica preocupada em distinguir o 'são' do 'não-são' ou do 'insano'. Assim certas pessoas apresentariam características de comportamento 'anormais', sintomas ou expressão de desequilíbrios e doença. Tratar-se-ia, então, de diagnosticar o mal e tratá-lo. (VELHO, 1974, p.11).
}

Tomando por base esta perspectiva, o indivíduo classificado na categoria de "doente mental" está imerso em uma rede de relações sociais, formada por diversas categorias sociais dispostas hierarquicamente num processo de contínua interação social. Assim, o "doente mental", sujeito de assistência médica e cuidado terapêutico do saber psiquiátrico, não é o ser natural e universal, mas uma construção sociocultural enquanto noção (VELHO, 1997). O indivíduo é muito mais do que um ser biológico. Ele é uma 
categoria social, membro de um grupo, de uma linhagem, de um clã, uma peça. Dessa forma, o indivíduo que faz uma leitura diferenciada da realidade social e age em oposição às ações dos grupos dominantes é enquadrado, segundo o seu contexto sociocultural, como "desviante". Esta classificação é fruto da reação social e não produto imperativo de uma natureza fisiológica, que dita pensamentos e atitudes ao sujeito. Posto que, "a identidade é construída a partir da condição de membro de uma coletividade, parte de um todo" (VELHO, 1997, p.101).

A respeito da noção de "doença mental" como uma categoria dotada de regulação moral é importante citar Duarte (2003). Nos estudos das experiências "saúde/doença", o autor definiu as "perturbações físico-morais" como situações que os atores vivenciam consideradas anormais, que afetam não só seu corpo, mas seu universo subjetivo e simbólico (moral, sentimentos e auto-representação). Dessa forma, as doenças mentais estão relacionadas a uma preocupação moral, na qual se julga certas experiências humanas como patológicas diante da ameaça às normatividades vigentes. Diante disso, cria-se a necessidade de intervenção na corporalidade, em prol da moralização da pessoa, a fim de preservar a ordem social. Portanto, as considerações de Duarte (2003) permitem ratificar as perspectivas moralizantes e de controle nos procedimentos terapêuticos institucionalizados pelo saber psiquiátrico.

A contribuição de Nobert Elias (2001) a partir da discussão sobre o "moribundo" aponta as dimensões da institucionalização do isolamento social que marcou o fenômeno da "loucura". Seu recorte teórico sobre envelhecimento, morte e o processo civilizatório corrobora a reflexão sobre o processo de asilamento sofrido pelos "doentes mentais" na hegemonia do saber psiquiátrico moderno.

Para o autor, a ideia da crença de que a morte pode ser adiada devido à elevação da expectativa de vida e os avanços das tecnologias do cuidado na medicina, nos últimos tempos, configurou um padrão de individualização e transformou as estruturas de personalidade, levando as pessoas a um excessivo autocontrole, a ponto de ocultar as emoções e evitar a sensibilização. Dessa forma, o impulso à individualização desencadeou o isolamento social e a solidão que fez com que a morte passasse a ser vivenciada solitariamente, já que os outros indivíduos deixam de se identificar com os "moribundos".

A morte também pode ser compreendida metafórica e processualmente: doentes, idosos e população em situação de rua tornam-se seres invisíveis e são 
destituídos do convívio social em instituições regidas por assistência impessoal e normas totalitárias e, assim, sofrem o processo de exclusão social para definitivamente morrerem isolados. Os "loucos" se identificam com esses "seres invisíveis". Os "loucos", que expressam existências socialmente sem significado para as exigências do sistema social, "morrem" interditados nos manicômios devido às suas "patologias/desvios".

As reflexões teóricas e conceituais dos autores citados, tomados para pensar a "loucura", produziram pares dicotômicos: "desrazão/razão", "doença mental /saúde mental", "desvio/padrão", "impureza/pureza", "patológico/ normal", "seres invisíveis/ seres visíveis". Dessa forma, de maneira crítica, embasaram os questionamentos sobre saberes e práticas do dispositivo da "loucura", a cada época em que se apresentam histórica e culturalmente. Para explorar a constituição das bases e da trajetória do movimento da Reforma Psiquiátrica Brasileira, que se coloca na contramão dessas dicotomias, suscita apresentar brevemente o surgimento e percurso do movimento da Reforma Sanitária no Brasil.

\section{A Reforma Psiquiátrica Brasileira: Novos Paradigmas no Campo da Saúde Mental}

Foi do reconhecimento da necessidade de repensar as práticas e políticas de saúde no Brasil que surgiu o movimento pela Reforma Sanitária. O Movimento Sanitarista surgiu da indignação sobre o dramático quadro da saúde, pautando sua ação pelo questionamento dos modelos de gestão e atenção nas práticas de cuidado e serviços de saúde.

As primeiras articulações do movimento sanitarista datam de antes do golpe militar de 1964, o movimento se fortaleceu no decorrer dos anos 1970 e 1980 e mantém-se mobilizado até o presente. Podemos afirmar que a Reforma Sanitária brasileira eclodiu vigorosamente em pleno contexto autoritário da ditadura reivindicando políticas públicas inclusivas e equitativas de saúde. Esse movimento estruturou-se nas universidades, no movimento sindical, no movimento popular e em experiências regionais de organização de serviços (LIMA et al., 2005).

O Movimento Sanitário construiu muito mais do que novos paradigmas em relação às práticas e tecnologias da saúde expressos através de um Sistema Único de Saúde, doravante SUS, criado na constituição de 1988 e regulamentado pela Lei 8.080 
em 1990. A Reforma Sanitária legou o ideário democrático como princípio norteador no enfrentamento às desigualdades de renda e de acesso aos serviços públicos, levando ao reconhecimento da saúde como direito de cidadania e obrigação do Estado. Fleury (1997) define a Reforma Sanitária como:

(...) um processo de transformação da norma legal e do aparelho institucional que regulamenta e se responsabiliza pela proteção à saúde dos cidadãos e corresponde a um efetivo deslocamento do poder político em direção às camadas populares, cuja expressão material se concretiza na busca do direito universal à saúde e na criação de um sistema único sob a égide do Estado. (FLEURY, 1997, p. 27).

Portanto, a Reforma Sanitária se configurou como um conjunto de políticas articuladas que incluíam tanto a transformação do paradigma sanitário, construindo um complexo alternativo de assistência, planejamento e gestão em saúde; quanto o estabelecimento do paradigma político através das lutas políticas e sociais como prática social, vinculando a ação desta Reforma - enquanto movimento ideológico comprometida com a transformação social, com exercício e efetivação da cidadania (PAIM, 1997).

O Movimento da Reforma Sanitária se organizou visando transformar o paradigma sanitário, dos anos de 1970-80 fundado na medicina curativa e na restrição do acesso aos serviços de assistência à saúde. $\mathrm{O}$ conceito de saúde reduzia-se ao cuidado da doença, enquanto a organização de serviços de assistência era voltada aos que podiam pagar por serviços de saúde privados e aos que tinham direito à saúde pública por serem segurados pela previdência social (FLEURY, et al, 1997).

A criação do SUS surgiu com a finalidade de superar a situação de desigualdade na assistência à saúde, que vem se materializando por meio de ações de promoção, prevenção e assistência à saúde. Essa mudança paradigmática deveu-se à ampliação do conceito de saúde como direito social, procurando garantir acesso integral, universal e gratuito para toda a população.

No tocante à organização da rede de assistência e da gestão dos serviços, SUS descentraliza as decisões, responsabilidades, atribuições e recursos sob controle do governo federal. A União, Estados e Municípios estabelecem redes de cooperação não hierarquizadas, com competências para cada um desses três gestores do SUS. A Lei 8.080 e Portarias do Ministério da Saúde definem atribuições a cada um para a 
promoção, proteção e recuperação da saúde, a organização e o funcionamento dos serviços correspondentes.

O modelo funcionamento e gestão do SUS inclui o cidadão não apenas como usuário dos serviços de saúde, mas também como participante da gestão do sistema. Por meio de dois mecanismos de participação: as conferências e os conselhos de saúde. Segundo Carvalho (1997, p.93), os conselhos de saúde e as conferências:

\begin{abstract}
(...) têm a atribuição de deliberar sobre a "formulação de estratégias e (exercer) controle sobre a execução da política de saúde na instância correspondente, inclusive nos aspectos econômicos e financeiros..." (Brasil, 1990). Desse sistema fazem parte também as Conferências de Saúde, fóruns que se reúnem periodicamente com a participação ampla de diversos segmentos sociais para avaliar e traçar diretrizes para as políticas de saúde.
\end{abstract}

Os conselhos de saúde são os órgãos de controle do SUS pela sociedade, de caráter deliberativo, nos níveis municipal, estadual e federal, cada conselho tem como missão deliberar, fiscalizar, acompanhar e monitorar as políticas públicas de saúde, permitindo à população interferir na gestão da saúde. Nas conferências, reúnem-se representantes de usuários do SUS, do governo, dos profissionais de saúde, dos prestadores de serviços, entre outros. As conferências são destinadas a analisar os avanços e retrocessos do SUS e a propor diretrizes para a formulação das políticas de saúde. Elas se dão em âmbito municipal, estadual e federal, a cada quatro anos.

O início da Reforma Psiquiátrica Brasileira é corolário das reivindicações da Reforma Sanitária no que diz respeito à demanda por mudanças políticas concretas no processo da redemocratização do Brasil. Essas reivindicações se manifestavam através da militância em movimentos sociais que reivindicavam transformações no panorama político, econômico e cultural do país.

Entretanto é importante ressaltar que apesar de contemporânea à Reforma Sanitarista, o movimento da Reforma Psiquiátrica é também resultado de um processo mais global, seus debates estavam vinculados à crise da psiquiatria no período pós Segunda Guerra. As expressividades das críticas diante das denúncias de maus tratos e desumanidade nos manicômios aumentaram, exigindo mudanças substantivas nos espaços asilares e no paradigma do tratamento psiquiátrico. 
De acordo com Birman e Costa (1994), essa crise da psiquiatria no pós-guerra, estava fundamentada em duas questões: a ineficácia das terapêuticas em voga, que ao invés de curar ou melhorar, levavam à persistência e agravamento dos sintomas, à cronicidade das "doenças mentais" nos espaços manicomiais, atestando a imperícia em tratar do assunto. A Reforma Psiquiátrica propõem então redirecionar o foco da psiquiatria para um novo paradigma: da promoção de "saúde mental".

Essa mudança paradigmática foi sendo construída por movimentos que rejeitavam a violência asilar e buscavam a transformação dos saberes e práticas do modelo psiquiátrico dado à "loucura". Portanto, no período pós Segunda Guerra Mundial, surgem, na Europa (França, Inglaterra e Itália) e nos Estados Unidos, os primeiros movimentos Da Psiquiatria Reformada, conforme batizada por Franco Rotelli (apud AMARANTE, 1995a) - Psicoterapia Institucional, Psiquiatria de Setor, Psiquiatria Preventiva, Antipsiquiatria e Psiquiatria Democrática.

Amarante (1995a) destaca a classificação estabelecida por Birman e Costa (1994) do caráter dos movimentos da psiquiatria reformada:

A psicoterapia institucional e as comunidades terapêuticas, representando as reformas restritas ao âmbito asilar; a psiquiatria de setor e a psiquiatria preventiva, representando um nível de superação das reformas restritas ao âmbito asilar; por fim, a antipsiquiatria e as experiências surgidas a partir de Franco Basaglia, como instauradoras de rupturas com os movimentos anteriores, colocando em questão o próprio dispositivo médico-psiquiátrico e as instituições e dispositivos relacionados. (AMARANTE, 1995a, p.27)

Em destaque na década de 60, na Itália, a Psiquiatria Democrática Italiana conduzida por Franco Basaglia (1982, 1991), denunciou os manicômios como instituições de violências, e propôs a construção de uma rede de serviços e estratégias territoriais e comunitárias, profundamente solidárias, inclusivas e libertárias. Esta ruptura teórico-conceitual e metodológica entre os saberes, discursos e práticas em psiquiatria instauraram um processo que, mais tarde, foi batizado de "Reforma Psiquiátrica". Esse movimento italiano influenciou fortemente a formação do movimento da Reforma Psiquiátrica brasileira, que mais tarde veio a ser conhecido como Movimento de Luta Antimanicomial.

Amarante (1995a) definiu a Reforma Psiquiátrica como: 


\begin{abstract}
(...) um processo histórico de formulação crítica e prática que tem como objetivos e estratégias o questionamento e a elaboração de propostas de transformação do modelo clássico e do paradigma da psiquiatria. No Brasil, a reforma psiquiátrica é um processo que surge mais concreta e principalmente a partir da conjuntura da redemocratização, em fins da década de 1970 , fundado não apenas na crítica conjuntural ao subsistema nacional de saúde mental, mas também, e principalmente, na crítica estrutural ao saber e às instituições psiquiátricas clássicas, no bojo de toda a movimentação político-social que caracteriza esta mesma conjuntura de redemocratização" (AMARANTE, 1995a, p. 87).
\end{abstract}

Tanto as reivindicações da Reforma italiana quanto as da brasileira iam muito além da orientação diferenciada no tratamento, assistência e atendimento aos pacientes psiquiátricos, mas objetivavam as transformações do imaginário social e das relações sociais marcadamente estigmatizadas, preconceituosas, e segregadoras para com estes sujeitos (AMARANTE, 1995b; 1996).

Portanto, o dispositivo da "loucura", isto é, o conjunto de saberes, práticas, instituições centrado na estrutura física e no perfil disciplinar, organicista e segregador do hospital psiquiátrico é colocado em questão, necessitando de reelaboração de um novo dispositivo. O movimento da Reforma Psiquiátrica é o ator social a pensar, conceber, construir e conduzir um inédito dispositivo da "loucura", que segundo Franco Rotelli (1990; 1992), ficou conhecido como processo de "desinstitucionalização" , que consistiu em desmantelar a instituição da "loucura", partindo da desconstrução da lógica e funcionamento do hospital psiquiátrico, para inventar outras estruturas que venham substituí-lo sob a perspectiva de redes inclusivas, integrando pessoas com "sofrimento psíquico" à sua rede familiar e comunitária.

$\mathrm{Na}$ perspectiva da Reforma Psiquiátrica, o processo de "desinstitucionalização" direcionou-se no movimento de desconstrução do modelo hospitalar de assistência e de construção de uma rede substitutiva para a reabilitação clínico e psicossocial em bases comunitárias e territoriais. Prosseguiu na revisão dos códigos legislativos sobre a condição jurídico-política dos pacientes psiquiátricos; na formulação, implantação e acompanhamento de políticas públicas de saúde mental, em seus princípios e diretrizes, a organizar e gerir os serviços substitutivos de assistência; reorientar os procedimentos epistemológicos, científicos, tecnológicos e terapêuticos; capacitar a atuação dos 
profissionais nas práticas de cuidado e atenção aos usuários dos novos dispositivos de assistência à saúde mental.

Retomando o conceito Foucaultiano, a "loucura" enquanto "dispositivo" - que compreende discursos científicos e morais, práticas medicalizadas, ações disciplinares e segregadoras, relações de poder e violência, edifício hospitalar, instituições totalitárias, entre outros $(1999,2000)$-, com a noção e o processo de "desinstitucionalização", foi se desconstruindo e configurando-se um novo arranjo para o "dispositivo da loucura": a) novos discursos e saberes científicos, b) novas organizações de serviços de assistência, c) novos princípios e diretrizes legais, d) novas políticas de estado de saúde, e) novas práticas de cuidado às pessoas com "transtornos mentais", f) renovação das instituições sociais, dos atores e seus papéis sociais e, g) novas relações e representações sociais sobre o "louco".

A "loucura" continua sendo institucionalizada enquanto um "dispositivo", estabelecendo um novo paradigma psiquiátrico, com saberes, práticas, locais de cuidado e promoção da "saúde mental". Nesse sentido, o que mudou foi a natureza dando novas dimensões a este dispositivo.

Considerações sobre a Teoria Ator-Rede de Bruno Latour (2000; 2012) contribui como valioso instrumento conceitual e prático, para refletir sobre a mudança paradigmática que o movimento da Reforma Psiquiátrica produziu, ao questionar os saberes e práticas médicas ancorados na psiquiatrização da "loucura" em "doença mental". Metodologicamente, Latour (2000) afirma que através do acompanhamento de cientistas e pesquisadores na sua atividade acadêmica de prática investigativa e empírica é capaz de compreender os discursos da ciência, pois segundo o autor, a ciência está fundada sobre uma prática, e não sobre ideias. Para tanto, elaborou a Teoria Ator-Rede, uma sistematização metodológica que analisa as relações sociais, e afirma que constituição das sociedades e suas instituições é consequência dos efeitos de redes (2000; 2012).

No entanto, os sujeitos imbricados nestas redes não são necessariamente sociais, referem-se tanto a atores humanos e a não-humanos que interligados a uma rede social de elementos constituem discursos e práticas sociais. Os indivíduos, as organizações, o maquinário, os grupos sociais, os objetos inertes, entre outros, constituem a trama de uma rede, onde o social é formado por elementos animados e inanimados. $\mathrm{Na}$ Teoria Ator-Rede tanto as pessoas quanto os objetos podem ser chamados de "ator" que se 
vinculam através de múltiplas conexões. Segundo este aporte teórico, o pesquisador das ciências sociais deve-se debruçar em descrever as associações produzidas por uma "rede de atores" para assim compreender os padrões e normatizações das instituições que se fazem presentes na vida social (LATOUR, 2000; 2012).

Nesse sentido, a Reforma Psiquiátrica, com seus princípios e diretrizes de serviços comunitários e territoriais, fundados na autonomia e liberdade civil, é consequência de uma rede de atores híbridas composta por elementos humanos e não humanos, que reconstruíram um novo "dispositivo da loucura" com vistas a um processo de "desinstitucionalização" do paradigma psiquiátrico centrado no hospital e na psiquiatrização da "loucura".

Constatou-se que tanto na Reforma italiana quanto na brasileira, o processo de "desinstitucionalização" visou muito além da orientação diferenciada no tratamento, assistência e atendimento aos pacientes psiquiátricos, mas requereram a garantia da autonomia e liberdade civil dos sujeitos em "sofrimento psíquico", bem como as transformações do imaginário social e das relações sociais marcadamente estigmatizadas, discriminatórias e segregadoras para com estes.

\section{Considerações Finais}

O movimento da Reforma Psiquiátrica brasileira organizou-se no sentido de rejeitar a violência asilar e os saberes e práticas centradas no hospital. Contudo, buscou redirecionar o dispositivo (FOUCAULT, 1997) que se constituiu em torno da "loucura", com o advento da Psiquiatria, para um novo paradigma: do tratamento da "doença mental" para a promoção da "saúde mental".

O processo de "desinstitucionalização" (ROTELLI, 1991,1992) que consiste na crítica ao modelo manicomial para o cuidado em saúde mental e na reorientação dos conceitos, saberes, valores e práticas estabelecidas com relação à "loucura" na sociedade, caracterizou as ações do movimento da Reforma. A regulamentação da Lei 10.216/2001 e as inúmeras portarias ministeriais formalizaram a desconstrução da lógica e funcionamento do hospital psiquiátrico, para configurar uma rede de assistência à saúde mental sob a perspectiva do tratamento humanizado e inclusivo, integrando pessoas com "sofrimento psíquico" à sua rede familiar e comunitária, para o processo de reabilitação clínica e psicossocial. 
O movimento da Reforma Psiquiátrica, também denominado de movimento de Luta Antimanicomial, ampliou a discussão da consolidação de uma rede integrada de cuidado e atenção em saúde mental para o debate de iniciativas sensíveis às demandas sociais dos usuários e seus familiares como a garantia da autonomia e reinserção ao mundo do trabalho. Mais ainda, as bandeiras do MLA também destacam a reorientação das representações sociais da "loucura": reverter o estigma de periculosidade e "doente mental" para o reconhecimento de múltiplas individualidades, segundo a noção de alteridade, diferença e diversidade.

No entanto, para superar o dispositivo histórico autoritário e disciplinador, a Reforma Psiquiátrica produziu novos conceitos, novas funções e novas percepções sobre a "loucura" relacionando-as à concepção de "saúde mental" em detrimento da noção de "doença mental".

A despeito destas demandas, Tenório (2007) constata que transformações na assistência e reformulação dos serviços de atenção à saúde mental no Brasil nos últimos anos foram radicalmente profundas, e que as discussões presentes no movimento da Reforma Psiquiátrica de outrora são hoje insuficientes. Portanto, é necessário repensar e enfocar sobre os novos problemas suscitados pelo amadurecimento da reforma, como por exemplo, a reflexão da clínica e da gestão dos serviços substitutivos já consolidados.

\section{Referências}

AMARANTE, Paulo. (Coord.). Loucos pela vida: a trajetória da reforma psiquiátrica na Brasil. Rio de Janeiro, FIOCRUZ, 1995a.

Novos Sujeitos, Novos Direitos: O debate em torno da Reforma

Psiquiátrica. Cadernos de Saúde Pública, 11 ( 3): 491 - 494, 1995 b.

O Homem e a Serpente: outras histórias para a loucura e a psiquiatria.

Rio de Janeiro, FIOCRUZ, 1996.

- Loucura, Cultura e Subjetividade. Conceitos e Estratégias, Percursos e

Atores da Reforma Psiquiátrica Brasileira. In: FLEURY, Sonia (org.), Saúde e

Democracia. A Luta do CEBES. São Paulo: Lemos Editorial, 1997. 
- Manicômio e loucura no final do século e do milênio. In: FERNANDES, Maria Inês Assumpção; SCARCELLI, Ianni Régia; COSTA, Eliane Silvia (Org.). Fim de século: ainda manicômios? São Paulo: APSO/ IPUSP, 1999.

\& COSTA, Ana. Diversidade Cultural e Saúde. Rio de Janeiro: Cebes,

2012.

BASAGLIA, Franco. A psiquiatria alternativa: contra o pessimismo da razão, o otimismo da prática. 3.ed. São Paulo: Brasil Debates, 1982.

A instituição negada: relato de um hospital psiquiátrico. 2.ed. Rio de

Janeiro: Graal, 1991.

BIRMAN, Joel e COSTA, Jurandir. Organização de instituições para uma psiquiatria comunitária. In: AMARANTE, Paulo (org) Psiquiatria social e reforma psiquiátrica. Rio de Janeiro: Fiocruz, 1994.

BRASIL, Lei no 10.216, de 6 de abril de 2001. Dispóe sobre a proteção e os direitos das pessoas portadoras de transtornos mentais e redireciona o modelo assistencial em saúde mental. In: BRASIL. Ministério da Saúde. Secretaria Executiva. Secretaria de Atenção à saúde. Legislação em Saúde Mental: 1990-2004. 5a ed. Ampl. Brasília: Ministério da Saúde, 2004.

Lei 8.080, de 19 de setembro de 1990. Dispõe sobre as condições para a promoção, proteção e recuperação da saúde, a organização e o funcionamento dos serviços correspondentes e dá outras providências. Diário Oficial da União, Brasília, DF, 19 set. 1990. Seção 1.

CANGUILHEM, G. O normal e o patológico. BARROCAS, M. T. R. de C. (trad.), 6, ed., Rio de Janeiro: Forense Universitária, 2006.

CARVALHO, Antônio Ivo de. Conselhos de saúde, responsabilidade pública e cidadania: a reforma sanitária como reforma do Estado. In: FLEURY, Sonia (org.), Saúde e Democracia. A Luta do CEBES. São Paulo: Lemos Editorial, 1997.

CASTEL, Robert. A Ordem Psiquiátrica: A idade de Ouro do Alienismo. Rio de Janeiro. Ed. Graal, 1978.

DOUGLAS, Mary. Pureza e perigo. São Paulo: Perspectiva, 1976. 
AVÍNCULA, G. A ressignificação do fenômeno da loucura e da assistência à saúde mental a partir do paradigma da Reforma Psiquiátrica. R. Cientifica UBM - Barra Mansa (RJ), ano XXII, v. 19, n. 37, 2. Sem. 2017. p. 19-38.

DUARTE, Luiz Fernando Dias. Individuo e pessoa na experiência da saúde e da doença. Ciência E̋ saúde coletiva. vol.8 no.1 Rio de Janeiro 2003.

ELIAS, Norbert. A Solidão dos Moribundos. Rio de Janeiro: Jorge Zahar Editor, 2001.

FLEURY, Sonia. A questão democrática na saúde. In: FLEURY, Sonia (org.), Saúde e Democracia. A Luta do CEBES. São Paulo: Lemos Editorial, 1997.

FOUCAULT, Michel. Vigiar e punir. Petrópolis: Vozes, 1977. . Resumo dos cursos do Collège de France (1970-1982). Rio de Janeiro: Jorge Zahar, 1997. . História da Sexualidade I: a vontade de saber. Rio de Janeiro: Graal, 1999. . Sobre a História da sexualidade. In: Microfísica do poder. Rio de Janeiro: Graal, 2000. História da Loucura na Idade Clássica. 9a ed. São Paulo: Perspectiva, 2010

GOFFMAN, Erving. Estigma: notas sobre a manipulação da identidade deteriorada. Rio de Janeiro: LTC, 1988. . Manicômios, Prisões e Conventos. 7. ed. São Paulo: Perspectiva, 2010.

LATOUR, Bruno. A ciência em ação. São Paulo: UNESP, 2000. Reagregando o social. Salvador: Ed ufba, 2012; Bauru. Sao Paulo: Edusc. 2012

LIMA, Nísia Trindade (Org.). Saúde e democracia: bistória e perspectivas do SUS. Rio de Janeiro: Ed. Fiocruz, 2005.

PAIM, Jairnilson Silva. Bases conceituais da reforma sanitária brasileira. Fleury, Sonia (Orgs). Saúde e democracia: a luta do CEBES. São Paulo: Lemos Editorial, 1997. 
ROTELLI, F. A instituição inventada. In: NICÁCIO, F. (org.) Desinstitucionalização. São Paulo: Hucitec, 1990.

. A experiência da desinstitucionalização italiana: o processo Trieste.

Saúde Debate, n.2, jun. 1992. (Cadernos Polêmicos)

TENÓRIO, Fernando. Questões para uma atualização da agenda da Reforma Psiquiátrica. In: COUTO, Maria Cristina Ventura e MARTINEZ, Renata Gomes (orgs.). Saúde Mental e Saúde Pública: questões para a agenda da Reforma Psiquiátrica.

NUPPSAM/IPUB/UFRJ, Rio de Janeiro, 2007.

VELHO, Gilberto. Relações entre a antropologia e psiquiatria. In: Individualismo e cultura: notas para uma antropologia da sociedade contemporânea. Rio de Janeiro: Zahar, 1997.

. O Estudo do Comportamento Desviante: A Contribuição da Antropologia Social. In: VELHO, Gilberto (org) Desvio e divergência, uma crítica da patologia social. RJ, Zahar, 1974. 